Strategy Communication and Transition Dynamics among Managers: A Public Sector Organization Perspective

\begin{tabular}{|r|l|}
\hline Journal: & Management Decision \\
\hline Manuscript ID & MD-11-2019-1589.R2 \\
\hline Manuscript Type: & Original Article \\
\hline Keywords: & $\begin{array}{l}\text { strategy communication, transition dynamics, top managers, social } \\
\text { practice, Middle managers }\end{array}$ \\
\hline \multicolumn{2}{|l}{} \\
\hline
\end{tabular}

SCHOLARONE ${ }^{\text {m }}$

Manuscripts 


\section{ABSTRACT:}

The purpose of this paper is to build on the research-supported view that interactions between top and middle management enhances effective implementation of organizational strategies by exploring the role of internal actors in driving organizational strategy at the intersection between strategy formulation and strategy implementation.

Adopting a social practice perspective, we undertook semi-structured interviews of 27 top and middle level managers drawn from a single case organization. Data collected was analysed using thematic analysis.

Differences in managerial perception of strategy has significant impact on implementation of strategic decisions as well as creating tensions in recursive communication practices between internal social actors. Furthermore, individual perceptions cannot only limit the extent of strategy awareness among key actors, the manifestations through social interaction between top and middle managers is a critical determinant of effective communication and realization of organizational strategy.

CUST_RESEARCH_LIMITATIONS/IMPLICATIONS_(LIMIT_100_WORDS) :No data available.

CUST_PRACTICAL_IMPLICATIONS_(LIMIT_100_WORDS) :No data available.

CUST_SOCIAL_IMPLICATIONS_(LIMIT_100_WORDS) :No data available.

The research contributes to the strategy process and practice literature by exploring the dynamic interactions taking place at the intersections of strategy formulation-implementation phases of organizational strategy. It particularly highlights practical issues in top and middle manager interactions and implications for successful strategy implementation. 


\title{
Strategy communication and transition dynamics among managers: a public sector organization perspective
}

\begin{abstract}
Purpose: The purpose of this paper is to build on the research-supported view that interactions between top and middle management enhances effective implementation of organizational strategies by exploring the role of internal actors in driving organizational strategy at the intersection between strategy formulation and strategy implementation.

Design/methodology/approach: Adopting a social practice perspective, we undertook semistructured interviews of 27 top and middle level managers drawn from a single case organization. Data collected was analysed using thematic analysis.

Findings: Differences in managerial perception of strategy has significant impact on implementation of strategic decisions as well as creating tensions in recursive communication practices between internal social actors. Furthermore, individual perceptions cannot only limit the extent of strategy awareness among key actors, the manifestations through social interaction between top and middle managers is a critical determinant of effective communication and realization of organizational strategy.
\end{abstract}

Originality/value: The research contributes to the strategy process and practice literature by exploring the dynamic interactions taking place at the intersections of strategy formulationimplementation phases of organizational strategy. It particularly highlights practical issues in top and middle manager interactions and implications for successful strategy implementation.

Keywords: strategy communication, transition dynamics, top managers, middle managers, social practice

Article classification: Research paper 


\section{Introduction}

In increasingly dynamic environments, organizations are surrounded with rapid, unpredictable changes, and a world of uncertainty requiring managerial competencies oriented towards strategic flexibility and ability to deal with changes in the business environment. These changes invariably require decision-makers to be alert, flexible and willing to employ innovative methods, in implementing their strategies. Whilst some researchers argue for the importance of engaging different mechanisms and processes for successful implementation of organizational strategies, others emphasize the insufficiency of appropriate processes without effective utilization and engagement, as these processes perceivably are key for managers in transitioning strategies from formulation to implementation (Grant, 2003). This paper employs social practice theory as an alternative approach to understand the effectiveness of constructs and processes in contributing to information flow within organizations and more so, the actual social practice of middle managers as enablers of strategy implementation. Furthermore, whilst the extant literature draws attention to the critical role of middle managers in strategy, there is a paucity of understanding of their actual contribution to driving strategy forward (Huy, 2011).

Furthermore, it is widely established in extant communications literature that effective communication plays a significant role in strategy implementation (Atkinson, 2006; KelvinIloafu, 2016; Shimizu, 2017). While some researchers identify tools and control systems important to enabling effective communications (Atkinson, 2006), others highlight social interaction factors that are contributory to the communications process (Okoe et al., 2018; Ozyilmaz and Taner, 2018). However, there is limited research outlining the underlying reasoning of key actors for their communication choices. In addition, many existing research centre on communications during the strategy implementation phase with limited consideration 
for other phases of the strategy process - before and after implementation. To address the identified gaps, our research interrogates perceptions of communication interactions between top and middle managers during the strategy formulation process, and the consequent impact for transition of formulated strategies to successful implementation. We thus investigate the engagement of middle managers in contributing to the strategy process, addressing the question 'how do middle managers contribute to strategy communication between the points of strategy formulation and implementation?'

\section{Theoretical background}

The strategic management process (SMP) essentially entails organizations being able to plan and adapt various operations for continuous business development (Dess et al., 2018). The strategy literature identifies three interdependent stages integral to SMP; formulation, implementation, and evaluation (Barney and Hesterly, 2018). However, success at one stage is no guarantee of subsequent success, nor of successful outcomes of strategic plans. Having devised strategic directions for the organization, top and middle managers would need to take and communicate appropriate implementation decisions, which may involve a range of organization actors. This is a sparsely explored area in literature, i.e. the role of managers in the communication process. We view middle managers as particularly integral to this process and thus investigate the positioning of middle managers in the communication chasm between strategy formulation and implementation.

As strategy formulation integrates elements such as mission statements, mandates, and recognition of core values, a clear understanding of these elements should enable middle managers to translate expectations of formulated strategies into practically implementable actions (Dess et al., 2018). In this regard, we view strategic planning as an organized process, which helps key stakeholders obtain information about environmental concerns, and translate 
these into implementable organizational goals and objectives. Barney and Hesterly (2018) further argue that strategy formulation is important for identifying external environment opportunities and challenges as well as assessing strengths and weaknesses arising from organizational resources and capabilities. While formulation is the first and integral step in SMP, it does not exist in isolation and if formulated strategies are to be successfully realized, it should not be an exclusive preserve of senior managers (Andersen, 2004).

Strategy implementation on the other hand represents a series of interventions involving key personnel, and systems designed to control performance with respect to desired outcomes (Greer et al., 2017). There is no consensus on appropriate definitions for the implementation stage. Some authors view implementation to be completed during the actual change process (Ukil and Akkas, 2017) others argue that it continues until successful realization of strategy (Köseoglu et al., 2020; Mišanková and Kočišová, 2014). In both instances, no clear-cut linkage exists between this stage and the preceding formulation stage or indeed in relation to the subsequent post-implementation stage (Audzeyeva and Hudson, 2016; Osnes et al., 2018).

Because strategy implementation involves managing resources to ensure successful delivery of proposed strategies, within reason, effectively formulated and organized strategies will yield better organizational performance (Dess et al., 2018). Although formulating a consistent strategy can be challenging, making strategy work through implementation can often prove more difficult. Equally, Schaap (2012) opines that execution of strategies is the most complicated and time-consuming part of SMP. This has precipitated increasing scholarly interest on barriers and factors influencing strategy implementation. For instance, Cândido and Santos (2019) identified 65 obstacles to strategy implementation, most of them associated with management control. Different schools of thought further suggest that strategy implementation failures are due to barriers such as; uncertainties/unexpected problems inherent in new 
strategies, inadequate shared understanding of new strategies, poor vertical communication, and employee resistance (Atkinson, 2006; Neilson et al., 2008).

For the occurrence of effective implementation, Rapert et al. (2000) further identify the need for shared understanding between top managers, middle managers, and the workforce. Clampitt et al. (2002) equally note, middle managers are more willing to engage in strategy communication but tend to see their role reduced to the tactical/operational level as opposed to involvement in strategic planning and decision-making. Invariably, existing research strives to identify the importance of middle managers in the communication process, however their role in the process remains unclear and the extent of engagement in promoting effective communication appears limited (Huy, 2002; Barry and Fulmer, 2004).

\section{Strategy communication process}

The importance of member interaction in strategy implementation is such that it fosters experience and value sharing, and invariably a sense of belonging that enables achievement of desired objectives (Bhattacharya et al., 2008; Obembe, 2013). Furthermore, management scholars have highlighted the critical role of communication in the strategy formulation and strategy implementation process (Ashcraft et al., 2009; Hallahan et al., 2007). Communication has been typically viewed as a one-way process of meaning construction in which the sender is the active agent constructing or reconstructing the meaning developed by the sender; or a two-way process in which both the sender and receiver are actively engaged in the process of meaning construction and reconstruction, with dialogue, interaction and feedback playing a key role (Obembe, 2010; 2013). An expanded view of communication, which is arguably best suited to effective strategy formulation and implementation, is the omni-directional diachronic process of meaning development. This process focuses on the social acts of senders and 
receivers in relation to the communicative process itself, and not so much on the relationship with each other. Based on this perspective, van Ruler (2018:379) defines strategic communication as "the management of the amalgam of communication processes in the context of continuous strategy development, and therefore include the presentation, promotion, and realization aspects as well as the building and rebuilding aspects of strategy and see this as a continuous loop".

Strategy communication is traditionally viewed as a responsibility of decision-makers, in influential positions and with key responsibilities. This typically involves the way in which top managers conceptualise organizational strategies and invariably transfer it to other employment levels, beginning with middle managers. Thus, Rouleau and Balogun (2011) noted that two sets of discursive activities, "performing the conversation" and "setting the scene", are critical to the accomplishment of sense-making. These enable middle managers to create an opportunity for shared strategic understanding and commitment. In addition, the right communication culture offers employees opportunities to engage with different organization hierarchical levels and ensure effective strategy implementation. For instance, Gim and Ramayah (2020) argue that top management need to be more engaged with subordinates in manners that promote interpersonal and informational justice, thereby minimising subordinates' propensity to stress conditions. Invariably, while managerial level roles may be well articulated (Huy, 2002; Rouleau and Balogun, 2011), communication could be adversely affected by cognitive inertia of middle managers where self-interests are threatened (Huy, 2011). This further suggests that managerial roles extend beyond systematic strategy processes to incorporating social interaction practices.

For Miller et al. (2008), top managers may engage middle managers in decision-making processes but rarely follow through to implementation. Similarly, Rigby et al. (2002) opine that middle managers often lack understanding of implementation requirements, which suggests 
improper communication and information flow breakdown at some point. However, the role of middle managers is increasingly recognised as going beyond direction and instruction provision, to change implementation facilitation (Jarzabkowski and Balogun, 2009). Hence, for middle managers to succeed in ensuring effective implementation of organization strategies, there must be more concerted interactions with top management (Obembe, 2010).

The omni-directional diachronic approach to strategic communication challenges the orthodox view of strategy communication, with regards to hierarchical relationships that typically define interactions between top managers and middle managers. By focusing greater attention on the communication process, rather than focusing only on relationships between the actors, the omni-directional approach provides a more effective approach through which middle managers, along with top managers, can engage more actively in a dynamic process of meaning construction from strategy formulation to strategy implementation (van Ruler, 2018).

\section{Middle managers and strategy practice}

Evidence from the strategy as practice literature supports the key role of middle managers in strategy implementation (Jarzabkowski and Spee, 2009; Vaara and Whittington, 2012). For instance, through formal and informal social network mechanisms, they ensure information accessibility and facilitate knowledge transfer, as well as promote employee development (Ahearne et al., 2014; Friesl and Kwon, 2016). As such, where middle managers are insufficiently engaged, successful strategy implementation may be significantly hampered (Mantere, 2005). 
Social practice provides an effective lens for explaining human interactions and particularly offers an alternative approach focusing on dynamic activities of managers in relation to other practices at organizations (Feldman and Orlikowski, 2011). Whilst elements of social practice theory find application in strategy studies, there is absence of commonality in their application as this differs from one field to another (Johnson et al., 2003; Jarzabkowski, 2008). For instance, some researchers provide descriptive approaches focusing on analysis of practitioner interactions and practices, and organizational praxis (Jarzabkowski and Spee, 2009). Others focus on applying personal applications of practices to explaining individuals' behaviour from varying employment level perspectives (Jarzabkowski and Kaplan, 2015). Furthermore, other established strategy theories do not adequately address the articulation of organizational interactions or how these drive strategies, hence the adoption of social practice theory in making sense of the dispositions of managers in communication processes.

Bringing the foregoing discussions together, we propose a new framework of omnidirectional diachronic approach to strategy communication (see Figure 1), to capture the role of middle managers through four phases in the strategy process: formulation, presentation, promotion, and realization/implementation. The process is presented as a cyclical loop through which the phases are enacted and re-enacted again to build and rebuild as may be required. We draw insights from the works of Hallahan et al. (2007), Rouleau and Balogun (2011) and van Ruler (2018) to highlight the communication activities of middle managers at four transition points between strategy formulation and strategy realization. At transition point 1 , we posit that the active involvement of middle managers, along with top managers, in strategy formulation, enables them to more effectively undertake what Rouleau and Balogun (2011) describes as "performing the conversation"- at the strategy presentation phase. Furthermore, at point 2, middle managers draw on their socio-cultural knowledge of the organisation to rally staff to achieve objectives. At point 3, between strategy promotion and strategy realization, the 
dynamic communication process between top and middle managers help the latter to revisit and revise (where necessary) and feedback to the employees. At the 4th point, between strategy realization and new strategy formulation, middle managers are able to act as the communicative bridge between top managers and frontline employees in the process of strategy re-building. Our present study focuses on the first two transition points.

\section{[Insert Figure 1 Here]}

\section{Methodology \\ Context, sample and data collection}

This empirical study is part of a wider exploratory study on transition dynamics between strategy formulation and implementation within Kuwait. The Kuwaiti public sector largely consists of different entities including; bureaus, agencies, ministries, charities, offices, and councils. The sector has overall control of development of the country's infrastructure in various fields, in terms of supervision and injection of required capital (Ramadhan and AlMusallam, 2014). Beyond operational oversight however, the Kuwaiti public sector's role extends to formulating strategies for, and implementing strategies across, its various entities. The case organization in this research, is one of the more active Ministries with extensive interaction with various public sector entities. At the same time, it provides a wide range of public services to the community. At the organization's request, the name of the ministry and the nature of its service provisions it provides cannot be disclosed. Kuwaiti public sector deviates from the norm as the role of public sector organizations entails regulation and supervision of the country's overall activities, and additionally formulation and implementation of government's public strategies (Ramadhan and Al-Musallam, 2014). The 
research aimed at gaining deeper understanding of relationship dynamics contributing to effective strategy implementation within a governmental ministry. So, we adopted a purposive qualitative approach using snowball sampling technique to conduct 27 semi-structured interviews (Roulston, 2010; Patton, 2015). See Table 1 below for interviewees' profile.

[Insert Table 1 Here]

As mentioned in the foregoing, the study aims to address the following research question: 'how do middle managers contribute to strategy communication between the points of strategy formulation and implementation?'. In line with the research question, the interview protocol was designed to ensure satisfactory responses on a range of issues including; managerial interactions, communication/analytic tools usage, individual awareness, communication openness, and strategic consensus. Interview questions were derived from the extant literature and designed to gain insights to managerial thinking and experiences in relation to strategy communication process, and strategy practices. The questions were grouped into two categories; the first set of questions were formulated to inquire more about the transition dynamics between the two strategy processes - formulation and implementation. The second set of questions was designed to shed light on the dynamic role middle managers played within the strategy practice. We also categorized the questions across two levels; essential, and probing questions to allow free-narrative responses. Each interview lasted between 45 and 90 minutes and in order to ensure adequate representation of perspectives on communication practices contributing to strategy implementation, similar questions were posed to both top and middle managers.

We adopted Castillo-Montoya's (2016), interview protocol refinement process in order to assure data quality and credibility. In this regard, the protocol was amended several times during its preparation, for better fit to the case context. Four pilot interviews were conducted 
to test the interview protocol, leading to minor revisions to questions to assure clarity (Patton, 2015). For instance, based on pilot interview feedback requesting for clarity, we refined how we conceptualised the terms 'strategy formulation' (development of organization strategy) and 'strategy planning process' (in reference to the whole strategy process).

The pilot was followed by an additional 23 interviews, all over a period of four months. As we relied on snowball sampling technique to identify respondents suitably qualified to contribute to the research aim, interview scheduling was guided by availability of the respondents. Nine interviews were rescheduled for varying reasons including; urgent conflicting meetings, unexpected work-related travels, annual leave, and sickness. As the research was exploratory in nature, geared at understanding the communications process and its implication for strategy implementation, we did not focus on specific organisation strategies and as such the time lapse between the interviews did not have significant bearing on responses provided between the early and latter responders. Furthermore, as we were intent on accessing a satisfactory pool of representative individuals with relevant knowledge and experience to contribute to the research, we opted for one of the long-standing ministries known to have a large presence of top and middle managers from different geographical backgrounds.

All but one of the interviews were conducted in Arabic by one of the authors and recorded with all ethics protocols duly observed. In order to assure data integrity, transcription and translation into English was done by the same author, and the transcribed interviews were reviewed by two independent language translators for verification. In total, the interviews generated 168 pages of transcribed data.

Data coding and analysis 
Following Corley and Gioia (2004), the interview data was analysed manually with responses initially open coded and further refined by recategorizing initial first order concepts into broader second order themes in order to inform our aggregated dimensions. The initial coding involved categorization of social practice factors into three strategy pillars; formulation, sharing (presentation and promotion), and implementation, and generated 57 potential subthemes. We coded for keywords/statements concerning middle managers' contribution to strategy formulation. This included responses on 'consensus', 'adoption', 'boundaries', and 'participation'. Similarly, for middle managers' contribution in strategy implementation ('realization', 'process', ‘managerial tools', 'manpower', and 'social norms and values'). Finally, references to aspects of communication e.g. 'direction of information', 'openness', 'sociability', and 'reciprocity', were coded as strategy sharing. After aggregating the code commonalities, three main themes were formed to provide answers for the research question under investigation. The themes are reported narratively based on the number of responses received to include, interaction mechanisms and organizational hierarchy, communication processes and managerial trust, and strategy transition, implementation and social interaction. Therefore, this practice of coding and merging data-sets was not only part of the data analysis process, but rather considered a part of the data reduction process. It is also noteworthy to report that within the process of data reduction, commonalities were linked and irrelevant codes were excluded. Table 2 below outlines the themes and code commonalities across the entire set of interviewees.

\section{[Insert Table 2 Here]}

Data was analysed using six stages of thematic analysis with descriptive label categories assigned for each theme/code, and presented as a narrative. The approach is commonly known to make qualitative research results available to a wider audience and it further provides researchers with the flexibility to compare theory and practice simultaneously (Braun et al., 
2019). Figures 2 and 3, represent a sample map of the associated data coding and the final thematic data structure, respectively.

[Insert Figure 2 Here]

[Insert Figure 3 Here]

\section{Empirical data and findings}

The findings demonstrate that societal culture and individual interaction mechanisms influence transition dynamics in strategy communication between top managers and middle managers. In this sense, they regulate the social interactions of both managerial groups in communicating an organization's intended strategy. However, we observed that the degree of communication between middle managers and both top management and frontline staff plays a critical role in the extent to which organizations realize their strategies.

\section{Interaction mechanisms and organizational hierarchy}

Empirical evidence from 23 of 27 respondents reflects how internal communication plays a crucial role in understanding transition of required strategies to staff members for final implementation, as exemplified by representative quotes demonstrating the influence of societal culture and interaction mechanisms below:

\footnotetext{
"Well...we try to understand the strategy as per the communication of our line managers, if they communicate it well, then we will be able to understand its content...if not, then we are not blamed if things go wrong! Right?” (I-2-MM)
} 
"I personally think understanding, as well as practicing, strategy is in fact a matter of communication, how clear is that communication, who communicates the strategy to who, and what channels and tools are used?". (I-16-MM)

The above representative quotes indicate that communication clarity is of prime importance to strategy implementation but additionally, the mechanisms employed in the communication process are equally important for successful implementation. Beyond this, respondents noted that the communication process seemed to be one-directional - a view expressed by 20 respondents and exemplified by the following excerpt:

"the information process is transferred in the form of paper orders that start from topto-bottom of the employment hierarchy..., this does not guarantee awareness of strategy itself by all employees across various levels...this is disappointing for anyone and that's why we have difficulties in implementing required objectives”. (I-1-MM)

Without two-way communication, top-down information flow is particularly problematic as communicated information may be limited thereby inhibiting employees' ability to comprehend and execute set strategies. Such top-down communication practices would give advantage to only a few staff with access to information whilst excluding a larger proportion of employees. Respondents also expressed dissatisfaction with respect to their passive involvement in decision-making processes. Additionally, respondent comments suggest that the middle managers' role entails acting as information conduits rather than facilitating and negotiating strategy decisions with employees. So, the lack of active participation hampers successful implementation.

In exploring how strategy transition is practiced, a top manager explained: 


\begin{abstract}
"We hold regular meetings at the top management level to discuss strategy...we are the only party involved in discussing such matters and we pass them accordingly to the relevant departments who then pass them to their staff for implementation. This makes it easy for us as it is difficult to involve all employees in discussions more so as the majority of them may not be interested!" (I-11-TM)
\end{abstract}

Here, the respondent views strategy formulation as exclusive to senior management with strategic decisions subsequently transitioned to lower managerial levels for implementation. This further supports the view of middle managers as being limited to delivering strategic information for execution without necessary involvement in the decision-making process. Fifteen respondents opined that a major reason for the lack of involvement of most employees in strategy communication is effectively due to their inability to engage significant numbers of employees. This is exemplified in the following quote.

"I guess they do not inform all of us because we have large numbers of employees who in fact could not add value to strategy related meetings!...they are there to do what they are told...the excessive number of employees we have is more than what we actually need...probably that's why we find our line managers always busy with their own duties! ...I think this is not healthy in the long run as we cannot support the organization with our technical experience”. (I-6-MM)

\title{
Communication processes and managerial trust
}

Perceptions on reasons for non-engagement of entire staff cohorts in strategy formulation varied across the organization hierarchy. In this regard, top managers opined that formulation is essentially strategic without need for consideration of technical details hence, lack of a desire 
to engage lower hierarchies of the organization. Individuals at this level are deemed to be actively involved with operational duties, which would preclude them from high-level strategic communications. In this case, mutual communication is seen as extra burden rather than a process for making implementation convenient:

"Why should we engage everyone...even departmental heads should not be aware of everything that goes on...they should only focus on their own department...the more people are engaged, the more complicated the process is and it's hard for us". (I-18TM)

"Obviously we are over-staffed, and this makes it difficult to organize the communication of our strategy...this means we cannot use certain tools or techniques in advancing our strategy even if we agree on the strategy itself! ...things might need reorganization between us and the departmental managers to be ideal and assure trust among us!”. (I-23-TM)

Beyond agreement on strategic decisions, there appears to be concerns with lack of consensus on communication tools and techniques. In this instance, the respondent advocates a need for re-organization to address inconsistencies in the top-middle manager communication process. Unchecked, such tensions would weaken reciprocity in communication:

"as long as communication depends on people rather than on the system, ...expect people to hide what they know from others..., it's almost chaotic, sometimes I do not feel that people are honest in telling us the truth of what is going on, they do not trust us or some of us...or even our performance capabilities...things should be the other way around!’”. (I-17-MM) 
The above exemplify a common view regarding trust levels between the top and middle managers, various departments, and frontline staff, which invariably contributes to inhibiting and delaying the strategy transition. That is, the tendency exists for managers to keep key information undisclosed due to lack of trust. Respondents further argued that strategy transition dynamics may not be systematic in organizing information flow, but depend on social practices of individuals. However, communication success among individuals may result in more organized workflow and less conflict within the organization. For instance, although respondent eight, a middle manager, considers staff at various levels as key sources for information sharing, where managers do not fully trust their subordinates, the tendency exists that they may not share their knowledge, which may result in limitations to staff effectively performing their tasks. Arguably one of the reasons for not sharing strategy is the underestimation of staff capability in performing required tasks. Past experiences and managerial pre-judgment could invariably contribute to delaying the transition process:

“...although encouraging communication could be healthy for our organization...we certainly believe that not all employees are trustworthy to accomplish the work, each has different capabilities...we tried them before, and we know to whom we should assign the work and pass the strategy". (I-18-TM)

"I will give you a real example, ok? I manage 20 employees, I treat them well, however, in terms of work issues, I trust the ability of only 5 or 6 as I know them, so why should everyone be unnecessarily engaged in communicating the strategy!?” (I-14-MM)

The above suggests that managers may have stereotypical views that affect their trust levels and invariably the extent to which they are predisposed to communicating strategies. Whilst a lack of trust between management and staff can act as an inhibitor to strategy communication, 
the existence of trust relationships may facilitate two-way communications and information sharing.

Another factor identified to limit communication is the perceptions of managers with regards to their staff. Amongst ministry employees, there is an apparent tendency to avoid engaging in any work requiring additional effort. This is exemplified by the following views:

"To be honest with you...we cannot blame only the management team for this issue... I mean, the majority of our staff are not interested in engaging in strategy and not willing to have extra workload!” (I-13-MM)

"Normally, employees here look to work with a soft manager who does not give them extra tasks... and headache, they want to be as relaxed as they can with little efforts!" $(\mathrm{I}-26-\mathrm{MM})$

"Our staff are employed by force due to the Civil Service Law, so how can we expect them to be interested in the strategy or whatsoever!” (I-4-TM)

Whilst on the one hand, there is the perception that employees may be disinclined to work hard, respondent observations also showed that employees tend to be reserved in sharing what they consider useful for enhancing strategy communication practices:

"I rarely share ideas; ideas don't reach the top of the pyramid except by a "mediator", or someone to connect me with the decision maker such as his relatives and of course after insisting several times to be in touch with him...there is no guarantee that my ideas and efforts will be appreciated, safely reach the right people, and be rewarded in return”. (I-26-MM)

As above, most respondents commented on the involvement of 'mediators' in the communication process. The actual Arabic word 'Wasta', translated here as mediator, refers to 
employees' feeling of the need for some sort of mediation to facilitate communication with higher management. In this regard, communication is selective across the managerial hierarchy to reach the right people in top management. The tendency exists for ideas to be kept secret if employees have had unpleasant experiences with their line managers. Where employees are not confident their ideas will reach the right individuals, communication is equally limited. Invariably, such concerns of distrust could limit creativity and implementation of strategic initiatives in the workplace.

\section{Strategy transition, implementation and social interaction}

Whilst there are significant variations in how managers deal with one another and with subordinates, most respondents identified the importance of consensus for strategy implementation process. Nineteen respondents noted that lack of consensus in both strategy process and practice among top and middle managers negatively affects their choice of tools and consequently the implementation of organizational strategy.

Although top and middle managers tend to agree on strategies for implementation, they experience conflicts in reaching agreement over suitability of processes for achieving strategic objectives:

\footnotetext{
"let me tell you, we cannot change the strategy, can we? But we have the expertise to manage which objectives should be given priority, the problem is how we process each of these objectives...we are not alone, and every engaged manager needs to prove something...we try to manage the practice by introducing benchmarking, KPIS, and other criteria...but we only try!" (I-4-TM)
} 
"I look at strategy and its implementation from a pure technical point of view, however, my manager looks at it from a pure managerial perspective... what I cannot accept is that they ignore our technical opinions and they inform us how to fulfil each objective!... there must be other acceptable tools as well that would be agreeable to both of us!". (I-22-MM)

In the above, whilst the respondents agree on strategies in place, the choice of mechanisms and tools for implementing the strategies are conflicting. Respondent four noted that due to managers having different perspectives, they were more inclined to ardently pursue their views, which may give rise to conflicts and invariably unrealized strategic objectives. Respondent 22 equally notes; differences in perspectives may give rise to tensions and inhibit the communication process during strategy transition. A common factor that many respondents identified as being key to dealing with disputes over communication of strategic objectives is social interaction between actors in the transition process - a view shared among 16 respondents.

To a large extent, regular strategy information is communicated through the social interaction networks between employees rather than through official channels. That is, employees tend to know about organizational activities informally through colleagues rather than formal line management channels. The role of social interaction in strategy transition dynamics was further highlighted as enabling respondents to deal with what was referred to as the cclosed door policy' culture. Respondents viewed that inflexible practices by line managers towards the staff indirectly encourages employees to interact more, seek informal alternatives during strategy implementation, and rely on their own personal choices:

"staff cannot reach an agreement on daily objectives or how they process things if they have no interaction with their managers by any means! ...staff at any level in this 
ministry are not entitled to counter risk because of deliberate or unintentional miscommunications by their line managers, right?... I cannot ignore the fact that it's a complicated process that affects both relationship-ties my choice of tools to meet required objectives!" (I-5-TM)

“...I think the issue of miscommunication depends massively on the direct line manager for each employee. People value listening to each other when managers adopt a closeddoor policy and there are a lot here...on many occasions, I personally take a decision and choose the appropriate tool, which I think is correct, to meet the assigned tasks to my department”. (I-12-MM)

The above excerpts suggest that communication among managers can be a complex dynamic process which cannot be taken superficially. Such complexity influences employees' practices and choice of mechanisms for transitioning strategies. This is the case as many employees view formal strategy communication channels may not be preferred by their senior managers, which makes them seek their own interventions. Furthermore, respondents noted that there is no single identified strategy practice, regarding communication processes, among both top and middle managers, which in turn contributes to interruptions in the transition dynamics of organizational strategy.

\section{Discussion}

Based on the research findings, there exists hierarchical distinctions amongst top management whereby not all top managers are actively engaged in strategy formulation processes. Five of the ten top management respondents argued that their role is limited to awareness of strategic 
objectives without the possibility of influencing the formulation process. Furthermore, none indicated they actually participated in strategy implementation. Additionally, the managers indicated that their role involved communication of strategy content without necessarily engaging in deliberations on content. This will invariably challenge the extent to which communicated strategy can be effectively transitioned and implemented. In relation to the first overarching theme on interaction mechanisms and organizational hierarchy, we noted from the middle managers' perspective, a lack of awareness of the organization's overarching strategy, as the majority of them were not involved in initial strategy formulation stages. Rather, their role appears limited to implementation of strategic objectives.

Existing research indicates that senior managers are often more than willing to communicate, but they often approach tasks on a strategic rather than a tactical level (Clampitt et al., 2002). Interestingly, nearly half of the middle managers argued that they do not take part in sharing the strategy with others, while others felt no obligations to communicate strategy with other employees. We however noted greater inclination for tactical level strategy communication among middle managers, as opposed to strategic level communications. In this context, middle manager functions appeared restricted to process orders and implementation of strategic objectives. In line with Rigby et al.'s (2002) view that managers may be unaware or not understand implementation requirements, middle managers tended to split into two groups; those communicating objectives as received and those passive in the strategy process. In both instances, the tendency for a primarily unidirectional communication approach hinders meaningful development and execution of organisation strategies (van Ruler, 2018) as the both middle managers and front-line staff are not adequately involved in conversations that shape the organisation's strategic direction.

Furthermore, although responses varied between managerial levels, the consensus was that ultimately strategy formulation decisions were determined by parties external to the 
organization and higher up in the ministry but this did not preclude engagement of internal actors in the strategy process. Middle managers opined that their roles were restricted to supervising and suggesting possible changes to pre-planned strategy. This runs contrary to extant literature which emphasises the importance of managerial involvement in forming organizational strategy (Miller et al., 2008; Schaap, 2012). However, others have argued that the strategy process should not rely only on key actors within the organization, but rather should involve all hierarchical levels in the organization (Friesl and Kwon, 2016; Cândido and Santos, 2019). Contrary to research advocating bottom-up strategic involvement of all in the organization (Andersen, 2004), even the few managers who were involved in the initial strategy formulation, were not involving their peers or subordinates in taking active roles in the strategy communication process. Thus, by restricting strategy formulation to a few key individuals, not only are the majority of the workforce disengaged, other middle managers themselves may become disengaged, which invariably limits the initial transition phase where enhanced conversations contribute to effective transition from formulation to implementation (Miller et al., 2008; van Ruler, 2018).

Secondly, with regards to communication processes, we note that the absence of documentation on organizations' strategy practices introduces additional complications to the process. Both top and middle managers concurred that whilst strategy may exist, they did not have a reference for reviewing the strategy content. Middle managers apparently see themselves as structurally informed rather than voluntary participants in the decision loop. This makes them act as information transformers rather than strategy facilitators. In this sense, there is passive engagement by managers in the strategy process; there is also a disconnect between formulated strategies and the implementation process as required tasks are communicated at face value, without recourse to the strategy formulators (Rouleau and Balogun, 2011). 
There is also a presumption by top managers that strategy delivered to subordinates are clearly understood and interpreted accordingly, which could be a sign of deliberate practice reflecting lack of reciprocity in engagement across managerial levels. This is in line with the view that communication bias may result from senior management's overconfidence and overestimation of the communication quality (Ghoshal et al., 1994; Friesl and Kwon, 2016). Such overestimation can however be addressed by both managerial levels actively engaging in the strategy process; particularly ensuring continuous feedback in the communication process in order to limit bias in the interpretation of strategy content. This view aligns with Mantere (2005), who asserts that where social actors are not enabled or empowered, they are unlikely to successfully realise the strategy process.

Furthermore, the findings highlight the existence of trust relationships (or lack thereof), among top managers, middle managers and front-line staff. In this instance, and in alignment with extant literature, we found that the lived experiences of individuals, whereby levels of trust in top management engagement were questioned, invariably increased the tendency for such individuals to share strategic information (Obembe, 2010; van Ruler, 2018).

Finally, an important aspect of strategy transition is the effective mobilisation and interaction of individuals integral to the process. In particular, respondents identified social interaction as a key factor for dealing with disputes over communication of strategic objectives. Ineffective communications between top and middle managers, coupled with low levels of trust resulted in tensions between the managerial hierarchy. Unchecked, such tensions limit interactions between actors in the strategy process, to the extent that top and middle managers only share what they deem relevant (Obembe, 2010; Rouleau and Balogun, 2011).

\section{Conclusion}


In this study, we have attempted to provide greater insight into how organizations can ensure effective transition of strategy from formulation to implementation by evaluating managerial interactions in the strategy process. We specifically observed the role of middle managers as key enablers of effective strategy execution. We suggest that the degree of communication and interaction between management and staff plays a critical role in the extent to which formulated strategies are transitioned particularly to the strategy presentation and strategy promotion phases. In this regard, it is the lack of consensus between top and middle managers that importantly hinders the functional role of middle managers in strategy communication and implementation.

We further contribute to the strategy as practice literature by emphasising the importance of social practice for strategy transition. In this regard, we outline the intricate role of social interaction between different actors in enabling strategy communication. That is, middle managers need to effectively engage with strategies rather than merely acting as strategy communication conduits. That is, continuous communication should be encouraged between formulators and implementers. We thus contribute insight to the acknowledgment of the growing importance of social practice perspective in strategy-making and execution (Vaara and Whittington, 2012; Rouleau and Balogun, 2018). This is especially the case for public sector organisations, the focus of our present study, where operational efficiency often acts as the main key performance indicator. This stands in comparison with other sectors, where innovation, creativity and competitiveness play more critical roles for organisations to achieve and maintain competitive advantage.

Whilst we have concentrated on gaining insight into strategy communications during the transition phase, there is further need for future research to focus on gaining a better 
understanding of communication dynamics across the entire strategy process spectrum. Specifically, our research proposed an omnidirectional diachronic framework for understanding communication during strategy transition. We explored the first two of the four key transition points for effective implementation of formulated strategies. There is therefore scope for future research to investigate unexplored aspects of the framework, to gain insight into the role of middle management communications in evaluation and monitoring of strategies, and enabling subsequent strategy development. In addition, our study targeted top and middle managers to explore their role in driving strategy forward, there is however scope for future research to similarly explore the role of front-line staff, and individuals in lower managerial roles, in sharing and implementing strategies. Future research can also be geared towards longitudinal investigation of the impact of aggregate themes.

In conclusion, our aim in this study has been to contribute to the understanding dynamics between strategy formulation and implementation in organizations by investigating the role of middle managers at the transition stage. Using communications and social practice perspectives, we have argued that effective transition of strategies is a function of the interaction mechanisms between top and middle managers. We further argue that lack of strategic consensus between top and middle management plays a major role in whether or not strategy is effectively communicated. It is therefore imperative that organizations wishing to ensure successful transition of their strategies, engage in developing meaningful communication protocols and engagement between top and middle managers. 


\section{References}

Ahearne, M., Lam, S. and Kraus, F. (2014), "Performance impact of middle managers adaptive strategy implementation: the role of social capital", Strategic Management Journal, Vol. 35 No. 1, pp. 68-87.

Andersen, T. (2004), "Integrating decentralized strategy making and strategic planning processes in dynamic environments", Journal of Management Studies, Vol. 41 No. 8, pp. 1271-1299.

Ashcraft, K.L., Kuhn, T.R. and Cooren, F. (2009), "Constitutional Amendments: 'Materializing' Organizational Communication”, The Academy of Management Annals, Vol. 3 No. 1, pp. 1-64.

Atkinson, H. (2006), "Strategy implementation: a role for the balanced scorecard?", Management Decision, Vol. 44 No. 10, pp. 1441-1460.

Audzeyeva, A. and Hudson, R. (2016), "How to get the most from a business intelligence application during the post implementation phase? Deep structure transformation at a U.K. retail bank", European Journal of Information Systems, available at: https://doi.org/10.1057/ejis.2014.44.

Barney, J. and Hesterly, S.W. (2018), Strategic Management and Competitive Advantage: Concepts and Cases, 6th Ed, Prentice Hall, London.

Barry, B. and Fulmer, I. (2004), "The medium and the message: the adaptive use of communication media in dyadic influence", Academy of Management Review, Vol. 29 No. 2, pp. 272-292.

Bhattacharya, C., Sen, S. and Korschun, D. (2008), "Using corporate social responsibility to win the war for talent”, MIT Sloan Management Review, Vol. 49, pp. 37-44. 
Braun, V., Clarke, V., and Hayfield, N. (2019), ““A starting point for your journey, not a map': Nikki Hayfield in conversation with Virginia Braun and Victoria Clarke about thematic analysis", Qualitative Research in Psychology, doi.org/10.1080/14780887.2019.1670765.

Cândido, C.J.F. and Santos, S.P. (2019), "Implementation obstacles and strategy implementation failure”, Baltic Journal of Management, Vol. 14 No. 1, pp. 39-57.

Castillo-Montoya, M. (2016), “Preparing for Interview Research: The Interview Protocol Refinement Framework”, The Qualitative Report, Vol. 21 No. 5, pp. 811-831.

Clampitt, P., Berk, L. and Williams, M. (2002), "Leaders as strategic communicators", Ivey Business Journal, Vol. 66 No. 50, pp. 50-55.

Corley, K.G. and Gioia, D.A. (2004), "Identity ambiguity and change in the wake of a corporate spin-off', Administrative Science Quarterly, Vol. 49 No. 2, pp.173-208.

Dess, G.G., McNamara, G., Eisner, A.B. and Lee, S-H. (2018), Strategic Management: Creating Competitive Advantages, McGrawHill, Berkshire.

Feldman, M. and Orlikowski, W. (2011), "Theorizing practice and practicing theory", Organization Science, Vol. 22 No. 5, pp. 1240-1253.

Friesl, M. and Kwon, W. (2016), “The strategic importance of top management resistance: extending Alfred D. Chandler", Strategic Organization, Vol.15 No. 1, pp. 1-21.

Ghoshal, S., Korine, H. and Szulanski, G. (1994), "Interunit communication in multinational corporations”, Management Science, Vol. 40 No. 1, pp. 96-110.

Gim, G.C.W. and Ramayah, T. (2020) "Predicting turnover intention among auditors: Is WIPL a mediator?", The Service Industries Journal, Vol 40 No.9-10, pp. 726-752, DOI: $10.1080 / 02642069.2019 .1606214$

Grant, R. (2003), "Strategic planning in a turbulent environment: evidence from the oil majors", Strategic Management Journal, Vol. 24 No. 6, pp. 491-517. 
Greer, C.R., Lusch, R.F. and Hitt, M.A. (2017), “A Service perspective for human capital resources: A critical base for strategy implementation", Academy of Management Perspectives, Vol. 31 No. 2, pp. 137-158.

Hallahan, K., Holtzhausen, D., van Ruler, B., Verčič, D. and Sriramesh, K. (2007), “Defining Strategic Communication", International Journal of Strategic Communication, Vol. 1 No. 1, pp. 3-35.

Huy, Q. (2002), "Emotional balancing of organizational continuity and radical change: the contribution of middle managers", Administrative Science Quarterly Vol. 47 No. 1, pp. $31-69$.

Huy, Q. (2011), "How middle managers group-focus emotions and social identities influence strategy implementation”, Strategic Management Journal, Vol. 32 No. 13, pp. 13871410.

Jarzabkowski, P. (2008), "Shaping strategy as a structuration process", Academy of Management Journal, Vol. 51 No. 4, pp. 621-650.

Jarzabkowski, P. and Balogun, J. (2009), “The practice and process of delivering integration through strategic planning”, Journal of Management Studies, Vol. 46 No. 8, pp. 12551288.

Jarzabkowski, P. and Kaplan, S. (2015), "Strategy tools-in-use: a framework for understanding technologies of rationality in practice", Strategic Management Journal, Vol. 36 No. 4, pp. 537-558.

Jarzabkowski, P. and Spee, A. (2009), "Strategy as practice: a review and future directions for the field", International Journal of Management Reviews, Vol. 11 No. 1, pp. 69-75.

Johnson, G., Melin, L. and Whittington, R. (2003), "Micro strategy and strategizing: towards an activity based view", Journal of Management Studies, Vol. 40 No. 1, pp. 3-22. 
Kelvin-Iloafu, L.E. (2016) “The Role of Effective Communication in Strategic Management of Organizations", International Journal of Humanities and Social Science, Vol. 6 No. 12, pp. 93-99.

Köseoglu, M.A., Altin, M., Chan, E. and Aladag, O.F. (2020), "What are the key success factors for strategy formulation and implementation? Perspectives of managers in the hotel industry", International Journal of Hospitality Management, Vol. 89 https://doi.org/10.1016/j.ijhm.2020.102574.

Mantere, S. (2005), "Strategic practices as enablers and disablers of championing activity", Strategic Organization, Vol. 3 No. 2, pp. 157-184.

Miller, S., Hickson, D. and Wilson, D. (2008), "From strategy to action: Involvement and influence in top level decisions", Long Range Planning, Vol. 41 No. 6, pp. 606-628.

Mišanková, M. and Kočišová, K. (2014), “Strategic Implementation as a Part of Strategic Management”, Social and Behavioral Sciences, Vol. 110, pp. 861-870.

Neilson, G., Martin, K. and Powers, E. (2008), "Strategy execution”, Harvard Business Review, Vol. 86 No. 6, pp. 61-70.

Obembe, D. (2010) 'Understanding Individual Action: When Employees Contravene Management Directives to Foster Knowledge Sharing', Management Research Review, Vol. 33 No. 6, pp. 656-666.

Obembe, D. (2013) 'Knowledge sharing, sustained relationships and the habitus', Management Learning, Vol. 44 No. 4, pp. 355-372.

Okoe, A.F., Boateng, H., Narteh, B. and Boakye, R.O. (2018) "Examining human resource practice outcomes and service innovation", The Service Industries Journal, Vol. 38 No. 7-8, pp. 431-445. DOI: 10.1080/02642069.2017.1397636 
Osnes, K.B., Olsen, J.R., Vassilakopoulou, P. and Hustad, E. (2018), "ERP systems in multinational enterprises: A literature Review of Post-implementation Challenges", Computer Science, Vol. 138, pp. 541-548.

Ozyilmaz, A. and Taner, D. (2018) "Communication skills shape voice effects in organizations", The Service Industries Journal. DOI: 10.1080/02642069.2018.1506444

Patton, M. (2015), Qualitative Research and Evaluation Methods (4th Ed). London: Sage Publications.

Ramadhan, M. and Al-Musallam, M. (2014), "The international experience in private sector development: Lessons for Kuwait”, Theoretical Economics Letters, Vol. 4 No. 4, pp. 279-288.

Rapert, M., Velliquette, A. and Garretson, J. (2000), “The strategic implementation process: Evoking strategic consensus through communication", Journal of Business Research, Vol. 55 No. 4, pp. 301-310.

Rigby, D., Reichheld, F. and Schefter, P. (2002), “Avoid the four perils of CRM”, Harvard Business Review, Vol. 80 No. 2, pp. 101-109.

Rouleau, L. and Balogun, J. (2011), "Middle managers, strategic sensemaking, and discursive competence”, Journal of Management Studies, Vol. 48 No. 5, pp. 953983.

Roulston, K. (2010), “Considering quality in qualitative interviewing”, Qualitative Research, Vol. 10 No. 2, pp. 199-228.

Schaap, J. (2012), "Strategy implementations: can organizations attain outstanding performance?", Strategic Management Review, Vol. 6 No. 1, pp. 98-121.

Shimizu, K. (2017) “Senders’ Bias: How Can Top Managers' Communication Improve or Not Improve Strategy Implementation?", International Journal of Business Communication, Vol. 54 No. 1, pp. 52-69. DOI: https://doi.org/10.1177/2329488416675449 
Ukil, M.I. and Akkas, M.A. (2017), "Determining success factors for effective strategic change: Role of middle managers' strategic involvement", Serbian Journal of Management, Vol. 12 No. 1, pp. 29-40.

Vaara, E. and Whittington, R. (2012), “Strategy-as-practice: Taking social practices seriously”, Academy of Management Annals, Vol. 6 No. 1, pp. 285-336.

van Ruler, B. (2018), "Communication Theory: An Underrated Pillar on Which Strategic Communication Rests", International Journal of Strategic Communication, https://doi.org/10.1080/1553118X.2018.1452240. 
Figure 1: An omnidirectional diachronic model of strategy communication

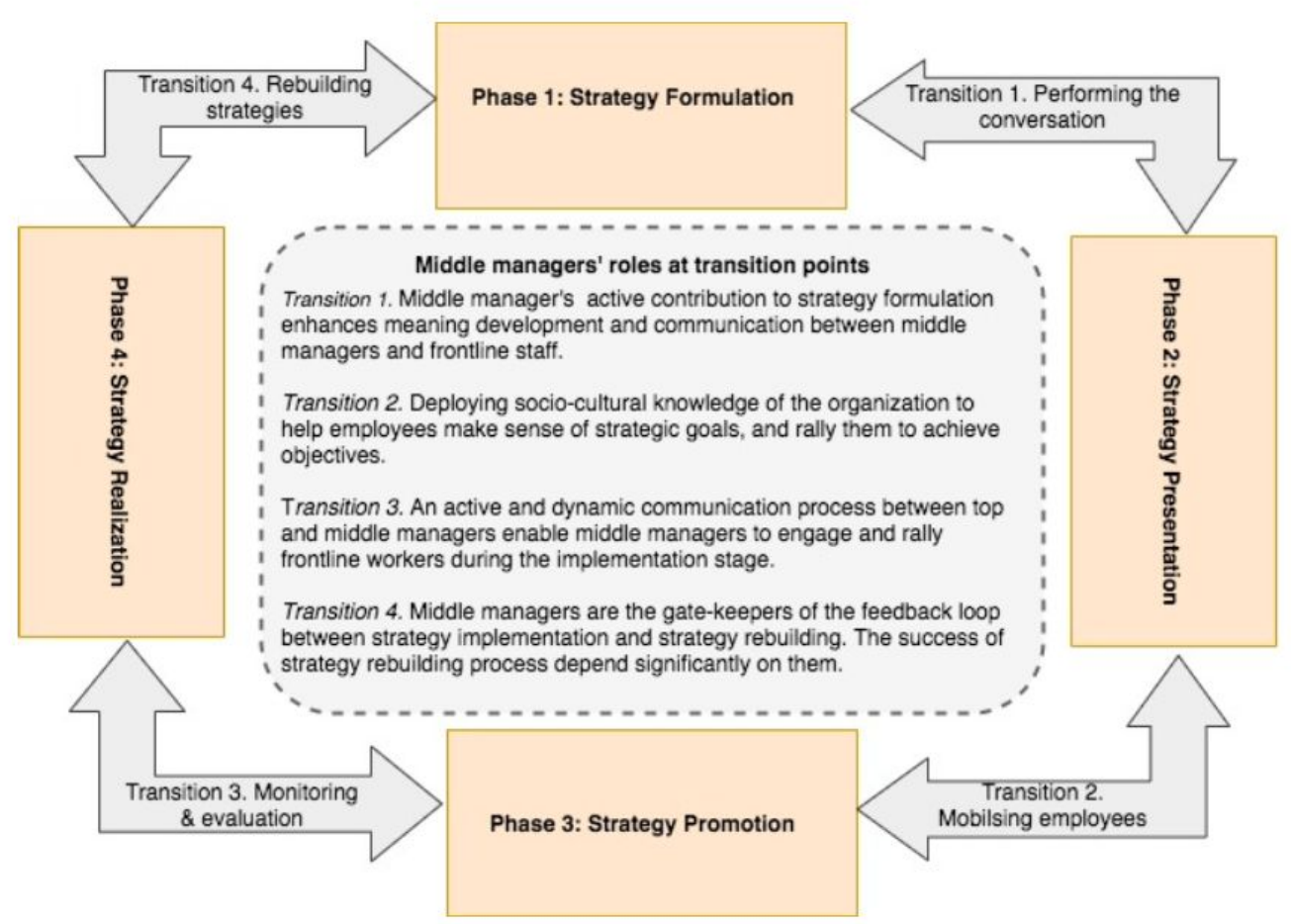

Figure 2: Sample map of data coding

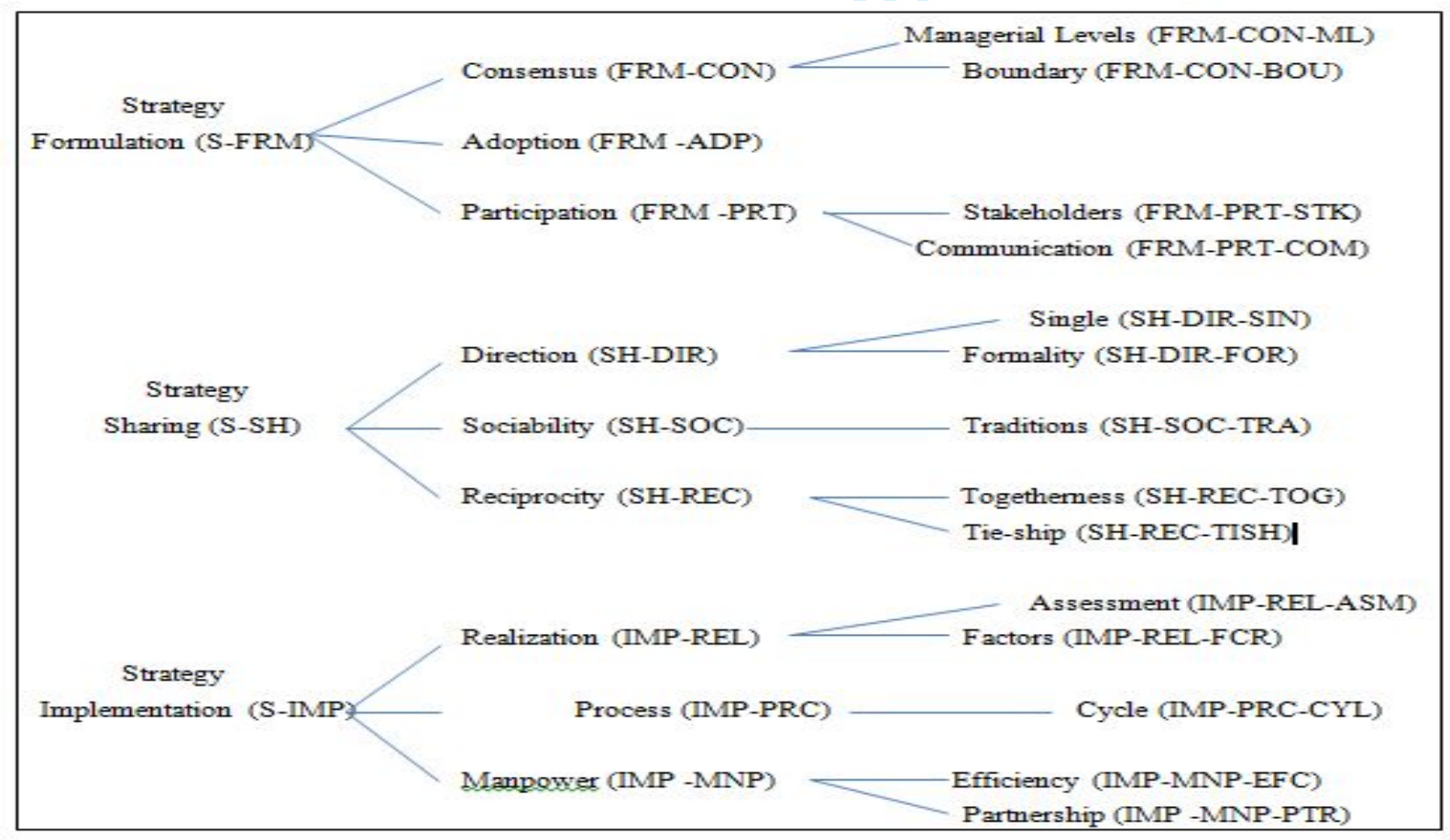


11 - Information follows top-bottom approach

12 - Communication is unclear, therefore unachievable!

16 Are we really involved in discussing the strategy?

17 • Our role including our experience is missing!

Figure 3: Thematic data structure

1st order concepts

2nd order themes

Aggregate

dimensions

19

21 In most cases, we are not engaged in the loop!

23 - Dictatorial decisions usually is dominance here

24

25

26

27 - Why they always undermine our technical abilities?

28 - I trust only those who belong to my social tribes

32 - We should be involved in the line of command!

33 - Their views are not always right, we don't care

We believe that not all employees are trustworthy

- I depend only one few or my work team

43 - If they don't agree, then we do what we believe in

44 - Why they should be the upper hand always?

48 Conflicting views become a routine here

- We prefer managers with influential social power

- Family traditions are appreciated and respected

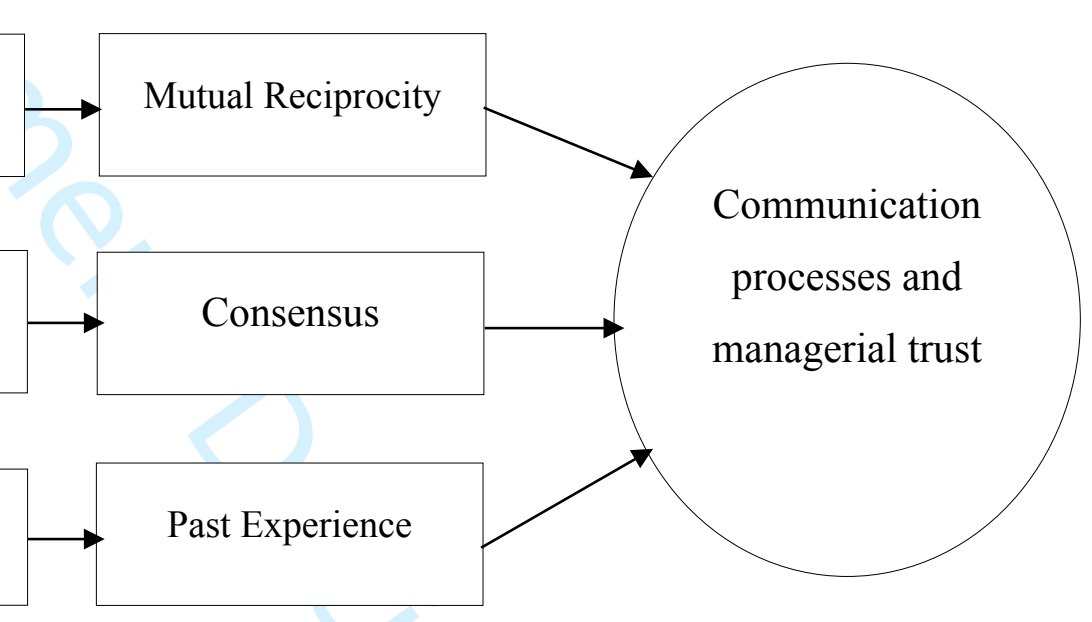

- Social connection "Wasta" is appreciated mostly!
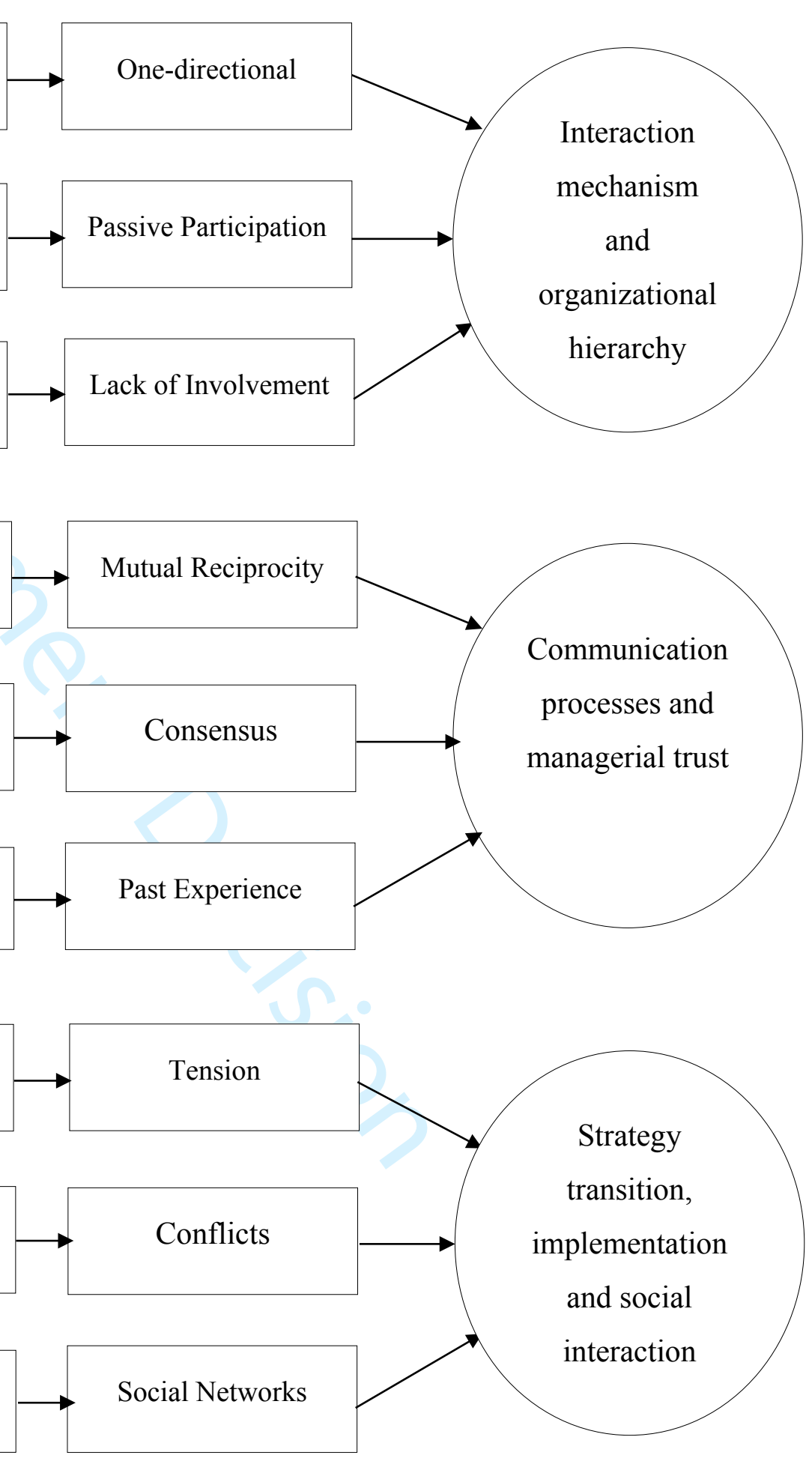
Table 1: Interviewees' profile

\begin{tabular}{|c|c|c|c|c|c|c|}
\hline $\mathbf{S} / \mathbf{N}$ & ID & Managerial Level & Gender & Managerial Role & Job Function & Experience \\
\hline 1 & I-1-MM & Middle Management & Male & Departmental Head & Project Supervisor & 8 Years \\
\hline 2 & I-2-MM & Middle Management & Female & Departmental Head & Supervisor in Supply Projects & 8 Years \\
\hline 3 & I-3-MM & Middle Management & Female & Departmental Head & Technical Support Team Leader & 8 Years \\
\hline 4 & $\begin{array}{l}\text { I-4-TM- } \\
\quad \mathrm{R}\end{array}$ & $\begin{array}{l}\text { Top Management } \\
\text { (Retired) }\end{array}$ & Male & Division Head & Manager in Control Unit and Surveillance & 10 Years \\
\hline 5 & I-5-TM & Top Management & Male & Division Head & Manager in Maintenance & 10 Years \\
\hline 6 & I-6-MM & Middle Management & Male & Departmental Head & Supervisor in Administrative Affairs & 8 Years \\
\hline 7 & $\mathrm{I}-7-\mathrm{TM}$ & Top Management & Female & Unit Head & Manager in Training and Research & 6 Years \\
\hline 8 & I-8-MM & Middle Management & Male & Departmental Head & Assistant Supervisor in Media & 8 Years \\
\hline 9 & I-9-MM & Middle Management & Male & Departmental Head & Networks Team Leader & 8 Years \\
\hline 10 & $\begin{array}{l}\mathrm{I}-10- \\
\mathrm{MM}\end{array}$ & Middle Management & Male & Departmental Head & Consumer Affairs Consultant & 8 Years \\
\hline 11 & I-11-TM & Top Management & Male & Division Head & Manager in Projects and Networks & 10 Years \\
\hline 12 & $\begin{array}{l}\text { I-12- } \\
\text { MM }\end{array}$ & Middle Management & Female & Departmental Head & Assistant Supervisor in Maintenance & 8 years \\
\hline 13 & $\begin{array}{l}\text { I-13- } \\
\text { MM }\end{array}$ & Middle Management & Male & Departmental Head & Quality Assurance Team Leader & 8 years \\
\hline 14 & $\begin{array}{l}\text { I-14- } \\
\text { MM }\end{array}$ & Middle Management & Male & Departmental Head & Consultant in Administrative Affairs & 8 years \\
\hline 15 & $\begin{array}{l}\text { I-15- } \\
\text { MM }\end{array}$ & Middle Management & Male & Departmental Head & Assistant Team leader in Legal Affairs & 8 years \\
\hline 16 & $\begin{array}{l}\text { I-16- } \\
\text { MM }\end{array}$ & Middle Management & Male & Departmental Head & Supervisor in Operation and Maintenance & 8 years \\
\hline 17 & $\begin{array}{l}\text { I-17- } \\
\text { MM }\end{array}$ & Middle Management & Male & Departmental Head & Supervisor in Technical Services & 8 years \\
\hline 18 & I-18-TM & Top Management & Male & Division Head & Manager in Networks Maintenance & 10 years \\
\hline 19 & $\begin{array}{l}\text { I-19- } \\
\text { MM }\end{array}$ & Middle Management & Male & Departmental Head & Supervisor in Technical Control & 8 years \\
\hline 20 & $\begin{array}{l}\mathrm{I}-20- \\
\mathrm{MM}\end{array}$ & Middle Management & Male & Departmental Head & Production Supervisor & 8 years \\
\hline 21 & I-21-TM & Top Management & Male & Division Head & Manager in Bids and Internal Affairs & 10 years \\
\hline 22 & $\begin{array}{l}\mathrm{I}-22- \\
\mathrm{MM}\end{array}$ & Middle Management & Male & Departmental Head & Employment Team Leader & 8 years \\
\hline 23 & I-23-TM & Top Management & Male & Division Head & Manager in Project Design & 10 years \\
\hline
\end{tabular}




\begin{tabular}{ccccccc}
24 & I-24-TM & Top Management & Male & Division Head & Manager in Financial Affairs & 10 years \\
25 & I-25-TM & Top Management & Male & Division Head & Manager in Planning and Follow-Up & 10 years \\
26 & $\begin{array}{l}\text { I-26- } \\
\text { MM }\end{array}$ & Middle Management & Male & Departmental Head & Assistant Team Leader in Internal Quality & 8 years \\
& & & & Assurance \\
& I-27- & Top Management & Male & Division Head & Manager in Training and Development & 10 years \\
& TM-R & (Retired) & & & & \\
\hline
\end{tabular}

Keys: I-TM: Interviewee from the top management; I-MM: Interviewee from the middle management; I-TM-R: Interviewee from the top management (Retired)

Additional note: due to ethical considerations and the request of the organizations, the job functions of the interviewees have been anonymized 
Table 2: Themes and code commonalities across the interview set

\begin{tabular}{|c|c|c|c|}
\hline $\begin{array}{l}\text { Aggregate } \\
\text { dimension }\end{array}$ & $\begin{array}{l}\text { Relative } \\
\text { themes }\end{array}$ & $\begin{array}{l}\text { Interview count: } \\
\text { (respondent ID) }\end{array}$ & Word similarities \\
\hline $\begin{array}{l}\text { Interaction } \\
\text { mechanism and } \\
\text { organizational } \\
\text { hierarchy }\end{array}$ & $\begin{array}{l}\text { One- } \\
\text { directional } \\
\text { Passive } \\
\text { participation } \\
\text { Lack of } \\
\text { involvement }\end{array}$ & $\begin{array}{l}23:(1-6,8,10- \\
13,15-22,24- \\
27)\end{array}$ & $\begin{array}{l}\text { Top-down, boundaries, needs } \\
\text { enforcement, participation, } \\
\text { direction of information, line of } \\
\text { command, Strategy ownership, } \\
\text { inactive role, unawareness, chaos, } \\
\text { autocratic style, unexpected } \\
\text { changes, misguidance, managerial } \\
\text { tools, one-man show }\end{array}$ \\
\hline $\begin{array}{l}\text { Communication } \\
\text { processes and } \\
\text { managerial trust }\end{array}$ & $\begin{array}{l}\text { Mutual } \\
\text { reciprocity } \\
\text { Consensus } \\
\text { Past } \\
\text { experience }\end{array}$ & $\begin{array}{l}20:(2-4,6-9 \\
12-14,17-18 \\
20-23,24-27)\end{array}$ & $\begin{array}{l}\text { Pre-judgment, personal } \\
\text { background, individual experience, } \\
\text { process, adoption, openness, } \\
\text { different mind-sets, unprofessional } \\
\text { practice, code of conduct, } \\
\text { alternative views, open door policy, } \\
\text { personal traits, grey area, lack of } \\
\text { clarity, suspension, } \\
\text { misinterpretation }\end{array}$ \\
\hline $\begin{array}{l}\text { Strategy } \\
\text { transition, } \\
\text { implementation } \\
\text { and social } \\
\text { interaction }\end{array}$ & $\begin{array}{l}\text { Tension } \\
\text { Conflicts } \\
\text { Social } \\
\text { networks }\end{array}$ & $\begin{array}{c}16:(4-5,7,11- \\
12,15-20,22- \\
24,26-27)\end{array}$ & $\begin{array}{l}\text { Manpower, social norms and } \\
\text { values, cultural phenomenon, } \\
\text { legitimate practice, mean of power, } \\
\text { social connections, tribes, personal } \\
\text { protection, lobbies, sociability, } \\
\text { realization, nepotism, positional } \\
\text { power, sense of authority, Wasta }\end{array}$ \\
\hline
\end{tabular}

